\title{
Coin-Based Mobile Charger using Solar Tracker
}

\author{
Nethravathi P. S. ${ }^{1}$, P. S. Aithal ${ }^{2}$, Sonia Soans ${ }^{3}$, \& Nayana Yadav ${ }^{4}$ \\ ${ }^{1}$ Professor, College of Computer and Information Sciences, Srinivas University, Mangalore. \\ OrcidID:0000-0001-5447-8673; Email ID: nethrakumar590@ gmail.com \\ ${ }^{2}$ Professor, College of Computer and Information Sciences, Srinivas University, Mangalore. \\ OrcidID:0000-0002-4691-8736; Email ID: psaithal@gmail.com \\ ${ }^{3}$ Lecturer, University of Technology and Applied Sciences, Sultanate of Oman. \\ OrcidID:0000-0002-4964-1197; Email ID: sonia.soans1234@gmail.com \\ ${ }^{4}$ HOD, Department of MCA, Shree Devi Institute of Technology, Mangalore. \\ Email ID: mnayanayadav@ gmail.com
}

Subject Area: Computer Science.

Type of the Paper: Research Paper.

Type of Review: Peer Reviewed as per $|\mathrm{C}| \mathrm{O}|\mathrm{P}| \mathrm{E} \mid$ guidance.

Indexed In: OpenAIRE.

DOI: https://doi.org/10.5281/zenodo.5506227

Google Scholar Citation: IJAEML

\section{How to Cite this Paper:}

Nethravathi, P. S., Aithal, P. S., Sonia Soans, \& Nayana Yadav, (2021). Coin-Based Mobile Charger using Solar Tracker. International Journal of Applied Engineering and Management Letters (IJAEML), 5(2), 68-77. DOI: https://doi.org/10.5281/zenodo.5506227

International Journal of Applied Engineering and Management Letters (IJAEML)

A Refereed International Journal of Srinivas University, India.

Crossref DOI : $\underline{\text { https://doi.org/10.47992/IJAEML.2581.7000.0104 }}$

(C) With Authors.

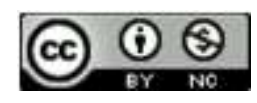

This work is licensed under a Creative Commons Attribution-Non-Commercial 4.0 International License subject to proper citation to the publication source of the work.

Disclaimer: The scholarly papers as reviewed and published by the Srinivas Publications (S.P.), India are the views and opinions of their respective authors and are not the views or opinions of the S.P. The S.P. disclaims of any harm or loss caused due to the published content to any party. 


\title{
Coin-Based Mobile Charger using Solar Tracker
}

\author{
Nethravathi P. S. ${ }^{1}$, P. S. Aithal ${ }^{2}$, Sonia Soans ${ }^{3}$, \& Nayana Yadav ${ }^{4}$ \\ ${ }^{1}$ Professor, College of Computer and Information Sciences, Srinivas University, Mangalore. \\ OrcidID:0000-0001-5447-8673; Email ID: nethrakumar590@gmail.com \\ ${ }^{2}$ Professor, College of Computer and Information Sciences, Srinivas University, Mangalore. \\ OrcidID:0000-0002-4691-8736; Email ID: psaithal@gmail.com \\ ${ }^{3}$ Lecturer, University of Technology and Applied Sciences, Sultanate of Oman. \\ OrcidID:0000-0002-4964-1197; Email ID: sonia.soans1234@gmail.com \\ ${ }^{4}$ HOD, Department of MCA, Shree Devi Institute of Technology, Mangalore. \\ Email ID: mnayanayadav@gmail.com
}

\begin{abstract}
Background/Purpose: Mobile phone industry is a booming industry in the market in the present times. This industry is growing tremendously not only in urban areas but also in villages. For communication and other various purposes people use Mobile phones. Hence the usage of mobile is much more that before ten years. In urban areas there are many resources available for charging but in rural areas most of the time charging facilities are unavailable and load shedding causes a lot of problems. Sometimes the battery becomes low during conversations or even an important transaction, and an urgent charging becomes necessary.
\end{abstract}

Objective: The major objective of this work is by inserting a coin in public places, one can charge the mobile phone. It will be helpful for the people who are suing mobile phones outside their homes/offices, need to use the coin based mobile phone charger to charge the mobile. $T$ To transmit and receive the IR (Infrared) signal, an IR transmitter and IR receiver will be used at the receiving end. A coin needs to be inserted between $I R$ transmitter and receiver, which will change the polarity of the pulses in Signal Conditioning Unit (SCU) input. To activate the $230 \mathrm{~V}$ charger, the relay will be ON and then the charger is used to charge the mobile phone.

Design/Methodology/Approach: Coin-based Mobile charger using solar tracker designed to provide a completely different service to people staying in rural areas. For controlling applications, 8051 microcontroller-based circuits used for programming. Power grid is the used for charging and the energy obtained from the sun is used when grid power is not available. MATLAB is utilized for coding to find the edge of the coin comparing it to the image clicked by the camera and to avoid coin duplication

Findings/Results: A simple and effective mobile charger has been implemented, which allow users to charge their phones in an emergency in public areas. This device uses very few components with a microcontroller 8051-based circuit. Usage of stepper motors allows accurate sun tracking. After reviewing the data, it was discovered that it is possible to capture good volume of sun energy when compared with fixed panel system. This method is more efficient, less costly and easier to use.

Conclusion: This work uses solar power as solar energy and generates more energy for free of cost. This system also uses external grid power in the absence of solar energy which will be helpful in the rural areas since villages face load shedding most of the time.

Paper Type: Research paper on the success story and contributing factors of coin based mobile charger using solar system.

Keywords: Mobile Charger, Solar Power, MATLAB, IR Transmitter, 8051 Microcontroller. 


\section{INTRODUCTION :}

Mobile phones are necessity now. Gone are the times when mobile phones were considered as luxury. Mobile phones are used for communication and for various purposes like bank transactions, gas booking, online payments, purchases, in fact everything that was being done physically outside the house is possible using a mobile phone. This leads to a major issue that is the usage of battery. Carrying a power bank is bulky and not dependable for a long time. Hence charging the phone is the utmost necessity now. If a person forgets to charge the phone before going out or is deprived of charging due to power failure at home, he is in a big problem. As simple as receiving the OTP during a bank transaction to making major usage of the phone, a charged phone is always a confidence for the user. This system is designed to charge a mobile when the mobile gets connected to a charging point in public. Initially a coin needs to be inserted. According to the type of coin the mobile will be charged and the percentage of charging will be shown. The Indian currency coins are utilized in this system. Based on the no. of coin inserted to system, number of mobiles can be charged at the same speed [1]. To avoid duplication of coins, a camera is used to take image of the coin and the same will be compared with the existing database. If a correct coin is detected with the match of the database, the mobile gets charged, otherwise it will display a message to insert the correct coin on the LCD screen. When the user fixes his mobile to the adopter and insert a coin, then, the phone gets a micro-pulse for charging, because it will depend on the currency to notify the percent of charge that the battery will get. Using image processing, the duplication of coin can be avoided.

For monitoring the mechanical movement of the solar panel, a stepper motor is used and LDRs are placed as the architecture of the proposed system. Depending on the movement of the sun, the intensity of the LDRs will change. If the light intensity of LDR is found to be less at any point of charging, then the stepper motor rotates where the LDR intensity less, finds the location of maximum energy of the sun while the ADC displays the reading with respect to the value of LDRs [2][3].

It is clear that the alternative sources of energies are spreading over the world [4]. Sun is one among the base for various energy, the light energy has an amazing charge. This light energy will be converted into electrical energy with this solar panel. The productivity can be improved by setting it towards sun direction [5]. The designed system offers a consistent and inexpensive for aligning a solar panel with the sun. Sun tracking software and simple circuit of microcontroller 8051 is used and the entire power is stored in lead-acid batter.

Now people are comfortable to use the smartphone, which offers latest technologies with best functionality like our personal computers [6]. These phones provide us advanced features namely internet, instant messenger and email facility et. Because of the huge growth in technology day by day, our needs also increasing and becoming more and more sophisticated, hence we need speed, quality and effectiveness [7]. All these features need to be combined in one place and small size. The life of the battery may not be matched with the new smart phone. Buying a phone is totally depending on the customers wants and needs.

It is fact that most of the consumers take their chargers along with them or some of them find in an airport terminal or in retailer etc. This need consumers to approach an outlet and they need to wait for long to charge their mobile phone. The designed charging system are mere band aids to the issue at hand. This system helps consumer to charge wherever they want. It is a general problem, sometimes battery gets discharged in the middle of the communication especially in important times. The designed system overcomes this issue.

The coin needs to be inserted into the insertion slot, then the system detects the coin with the help of a sensor. The mobile will be connected to the charging plug and starts charging with the help of this system.

Initially, when the phone is inserted, the coin is needed to be kept in the slot, it compares the images of the coin with the existing database. If it finds new coin, then it will show on the LCD. Then the mobile will be connected, then charging starts and it depends on the value of the coin. Based on the value of the coin the charging can be Increased. This system can recognize coins of rupees 1, 2, 5 and 10. The LDRs rotates based on the suns energy and obtains maximum sunlight.

Keil programming is used to design the system and installed into the microcontroller by using Flash Magic and MATLAB is used for coin detection. During the night when it is dark or in rainy season, it can be connected to an external power supply also. The system works in both the conditions. 


\section{OBJECTIVES OF THE STUDY :}

(1) To study the use of coin-based method to charge mobile phones in public places.

(2) To analyse the effectivity of usage of phones outside without the charging condition.

(3) To study the IR (infrared) transmitter and receiver in signal transmission.

(4) To research the effectiveness of inserting a coin between the IR transmitter and receiver.

\section{LITERATURE SURVEY :}

The designed system is unique and can be installed in rural/semi-urban areas. It can be used as people as utilities in public places. This system uses microcontroller, which countdown time for a3 minutes. With the help of LCD display the completing time and actual time left will be showed.

Where the electricity supply is not available all the time and not possible to access grid power, then this system is very helpful. This system is very flexible to use. User need to fix his mobile phone into adopter and placing a coin.

This product works based on the according to the coding written in the 89c51 microcontroller IC. The detector finds the coin and the input is given to the controller. Atmel89c51 microcontroller is used and the charging time period is calculated by using Atmel 89c51 microcontroller.

The survey is executed to know the similar type of work done so far. It is found that, the solar energy/power used to dry or preserve things from ancient times. Vedic literatures also say that, the use of flying machines is powered using the sun [8]. Many research works carried out in designing solar cells. These solar cells and kept in an arrangement to get the required power. P-n junction semiconductor devices doped with ' $\mathrm{n}$ ' type phosphorous on the top and ' $\mathrm{p}$ ' type boron on the base. When PV cell kept in the sun, then photons of light strike the electrons and helps to knock p-n junction free of their atoms. Electrons attracted to the positive charge and repelled by negative charge and then connecting wires between the junction the electricity pass in them [9].

Generally, the solar panel faces in one direction as it does not get enough rays of the sun to generate energy [10]. The maximum power optimization will be done to receive more energy from the sun by using LDR. A servo motor is connected through the solar panel. This unique system is helpful where unavailability of grid power [11][12]. Once the user plug in mobile phone into adapter and place a coin, the phone, it charges with micro-pulse. The charging capacity will be displayed with the predefined values. User can continue charging by placing a greater number of coins placing one after the other. As number of mobile users increasing day by day in rural areas, this product is helpful for the common public. For controlling applications, a suitable microcontroller is programmed and this system is very compact and lightweight as well.

In case of absence of solar power, the power grid is utilized to run this system. Two different axis tracking mechanism are available. Single-axes tracker follows the sun's east-west movement, whereas two-axis follows sun's altitude angle. A tracking system follow the sun with some specified degree of accuracy and return the collector to its original position at the ned of the day. The conventional sun trackers have a closed-loop control system function, whereas this product can be used with peak power positioning [13]. Operational Amplifiers are used in these types of systems.

\section{METHODOLOGY :}

This solar based charger system converts light energy into DC current for a range of voltage for charging purpose [14][15]. A coin insertion slot is a machine-driven space is attached with electrical triggering. Following figure-1 explains the step-by-step procedure of the system.

$\checkmark$ User can start the system by placing the coin

$\checkmark$ IR sensor detect the inserted coin

$\checkmark$ If detected, then charging will start, otherwise refund the coin.

$\checkmark$ User connect the charger to mobile

$\checkmark$ If more coins added to increase charging. 


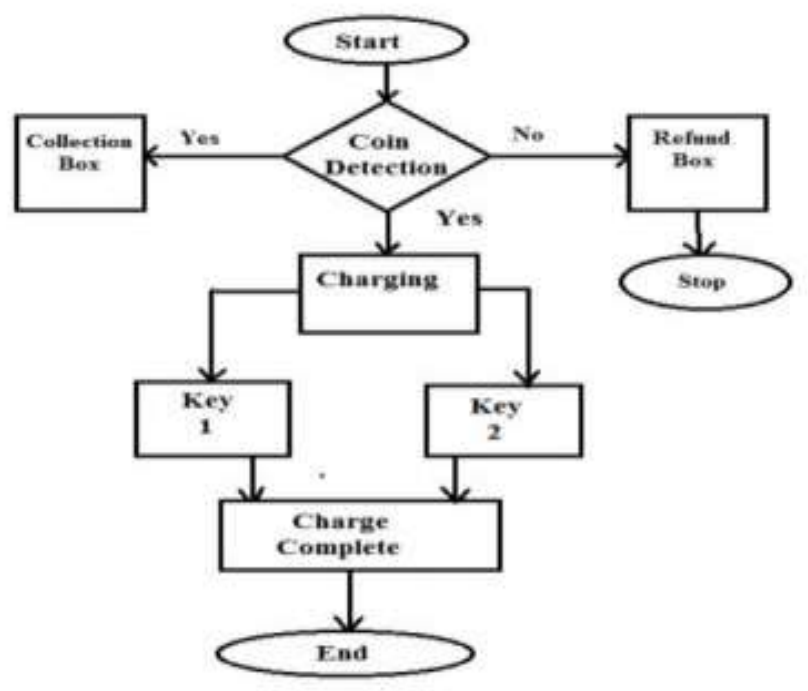

Fig. 1: Working of the system

The different sessions implemented for the implementation of this work as follows:

\section{Input \& Controller:}

A sensor controller, a keypad, a collector and a refund box is fixed in this part. In the beginning, the user inserts the coin then it is checked by a sensor. Sensor is nothing but a load cell, mostly used for digital weight machine. Load cell detects the coin weight and generates some values in terms of voltage. ADCs output is given to the controller; the ADCs value is checked with already stored coin value. If the value does not match then the alarm rings and a message is displayed as "coin duplicate" on LCD display and coin outside by refund box. If coin is original, then message display "coin original" on LCD display and coin collected by collecting box. Controller is a main part of this work. It controls the relay by applying gate pulse, operate DC motor using relay and driver IC and operate stepper motor by programming. All programs will be executing in Keil Uvision 4 and the circuit is run on Proteous simulation. Charging time is 45 minutes as per Rs. 5. Cost of electricity and miscellaneous cost includes the Rs.5.

\section{Output Unit:}

Charging probes and collecting box are including in output unit. When the coin is detected and user selects any option Ex. Press 1 for mobile charging then $1^{\text {st }}$ relay is ON for 30 min. After 30 mins charging automatically puts OFF.

The system is designed by using an IR transmitter and receiver for sensing the coin. After placing the coin, it cuts radiation for a second. When it gets interrupted, the receiver gives the pulse output to the SCU. Here comparison of input signal and reference voltage are done. If the sensor input exceeds threshold value, the output value is high. The obtained output is fed to the inverter circuit to invert the pulse to low. This converted low pulse is given to 555 timers as a trigger input. As soon as trigger is received, the output from this is used to trigger the realia for pre-defined interval.

\section{Algorithm for mobile charger}

- Start

- Coin Detection. If correct coin is detected, then the coin goes to collection box and switch is ON. And if incorrect coin is detected this coin is go to the refund box and stop the process.

- When switch is on for the charging then charge the Phone (At a time we can connect three to five phones).

- According to the coin battery will charge up to some percentage.

- Once charge the battery up to the given percentage it will stop charging.

Charge Mobile (coin)

Input: Coin.

Output: Charging......

Process: 
Display "Please insert coin"

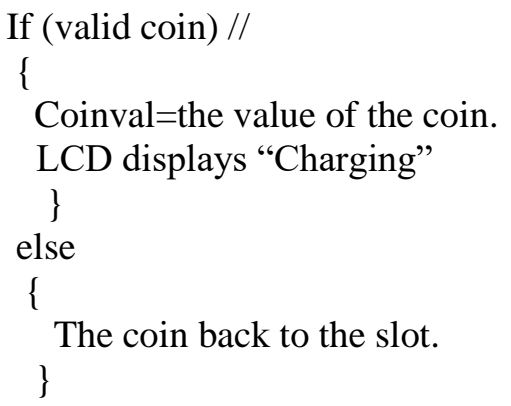

Input operations will be carried out in the system are:

With the use of MATLAB source code, the output for coin detection output can be seen here. The following figure 2 below displays the input consists of 'get live', 'Read Image', 'process' parameters. It consists an image of coin live called 'get live', for reading the image 'Read Image' and to compare with originally stored image it uses 'process' parameters to send the output.

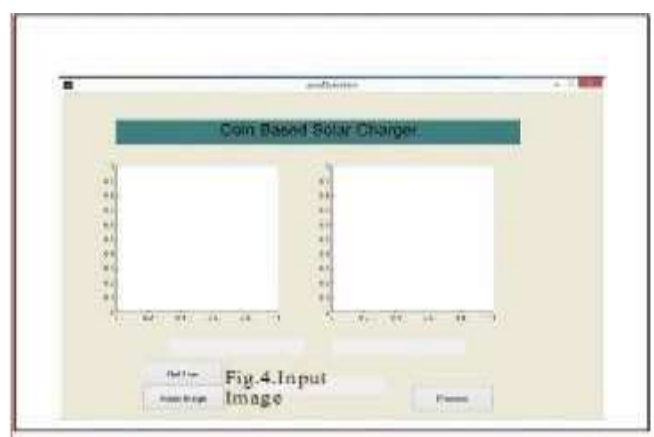

Fig. 2: Input Image to be taken for Detection

In figure 3 below, shows the image taken by the camera and gives the result "Metric Closer to 1 Indicates the Image is Perfectly Round".

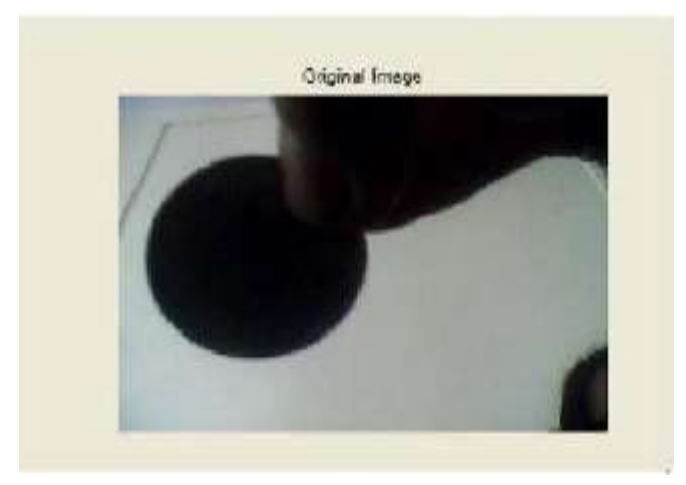

Fig. 3: Image for detecting shape of the coin

Figure 4 tells us the MATLAB platform for edge detection where according to the edge of the coin its size we can find out the coin prediction where the density and weight can be used to find the coin correctly. 


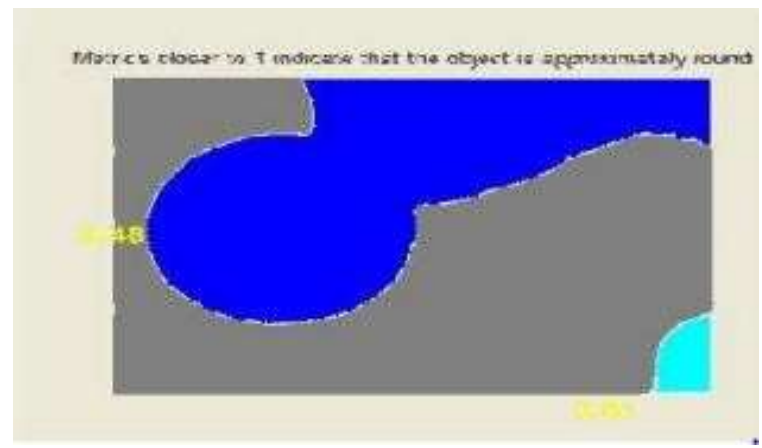

Fig. 4: Coin Edge Detection

Below in figure 5 one can see that the input image taken by the MATLAB platform to detect the real image test to test its originality as the MATLAB used to compare the size of the coin followed by the image captured.

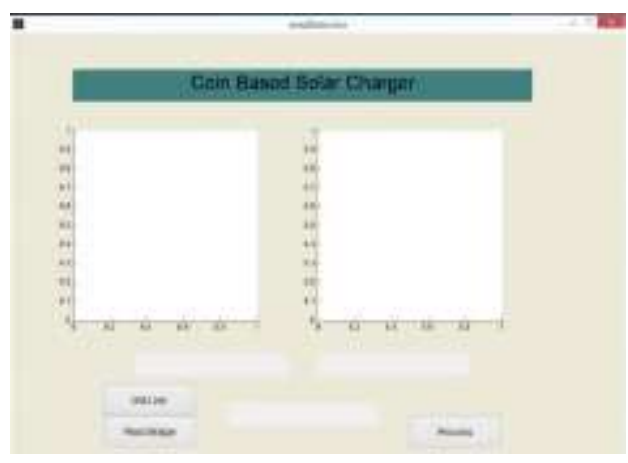

Fig. 5: Input Image

The image of a coin taken by the web camera that is attached to the system. As we take the images of the coin to test the originality from all the dimensions possible is shown in figure 6.

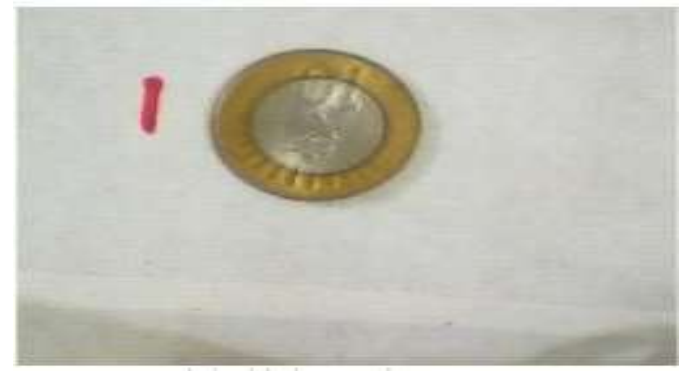

Fig. 6: Original Image Taken by the Camera

MATLAB code utilized for detecting the edge of the con with comparing to image clicked by the camera. Here we can see that the camera image along with comparison to detect the con's edge by comparing it to a picture captured by the camera. The camera image, as well as a comparison in the source code shown below. 


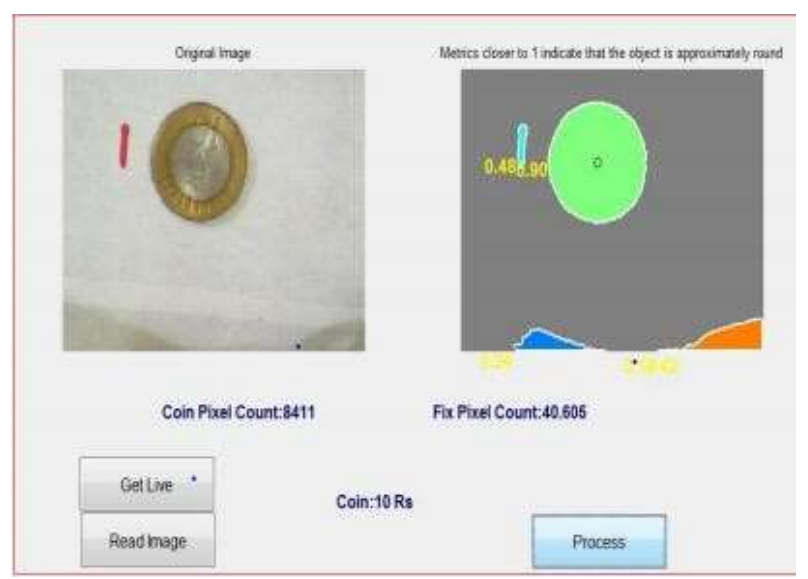

Fig. 7: Edge Detection Comparison with camera

In this figure we can see the comparison of the edge detection of the coin is being calculated where we compare the thickness of the coin. The thickness of the coin helps us to find about the originality of the coin.

\section{Different types of phones with different capacities:}

Here are different types of devices with different capacities available. It is known that the battery ranges of all the devices vary according to their capacities by using in this system. In the given devices the devices when gets completely charged a signal is send indicating that the device is about to get charged completely. So, these are some of the devices with different battery capacities shown in table 1 below.

Table 1 : Charging Capacities of various brands

\begin{tabular}{|l|l|l|l|}
\hline No. & Device Brand & $\begin{array}{l}\text { Charging (Max) } \\
\text { Voltage (V) }\end{array}$ & $\begin{array}{l}\text { Charging } \\
\text { (Maximum) } \\
\text { Current (oh) }\end{array}$ \\
\hline 1 & Nokia & 4.8 & 1500 \\
\hline 2 & LG & 5.5 & 2100 \\
\hline 3 & HTC & 5.5 & 1800 \\
\hline 4 & Panasonic & 3.7 & 1200 \\
\hline 5 & Black Berry & 3.7 & 1300 \\
\hline 6 & Samsung & 5.7 & 3400 \\
\hline 7 & Sony & 4.8 & 900 \\
\hline
\end{tabular}

The components used for this system are soldered on a PCB. Testing of regulator circuit is performed by connecting voltage between $8 \mathrm{~V}$ and $18 \mathrm{~V}$ as the input to voltage regulator. It is observed that the output is constant and the value of the voltage between $4.55 \mathrm{~V}$ and $5.25 \mathrm{~V}$. The circuit woks efficiently for this value. After testing, the negative output of the regulator is connected to the -ve of USB, positive to +ve point of the USB port. At the end solar panel is connected to the input of the voltage regulator. During testing it is observed that $5 \mathrm{~V}$ output voltage during sun light. This is the ideal voltage to connect the mobile phone for charging.

The charging is depending on coin inserted. According to diameter of coin, image of coin the battery will charge. That images store in database of system hence we can find the originality and the battery will charge.

\section{RECOMMENDATIONS AND CONCLUSION :}

A simple and hand efficient mobile charger is implemented and it helps consumers to charge their phones in public places when they are away from their home/office. This product designed by using minimum number of components with the microcontroller 8051 and a stepper motor to enable exact chasing of sun. After texting, it has been shown that the sun tracking systems can collect maximum energy than a fixed panel system with improved efficiency. 
The hardware setup for coin based mobile charger using solar tracking system shown below, this setup contains following hardware parts: LDR 1, LDR 2, ATMEL 89c51 Microcontroller, Stepper Motor, LCD Display, Motor Driver, Solar Panel, Battery, Coin Detected IR Sensor, Power Supply Unit. The hardware is as shown below in figure 8 .

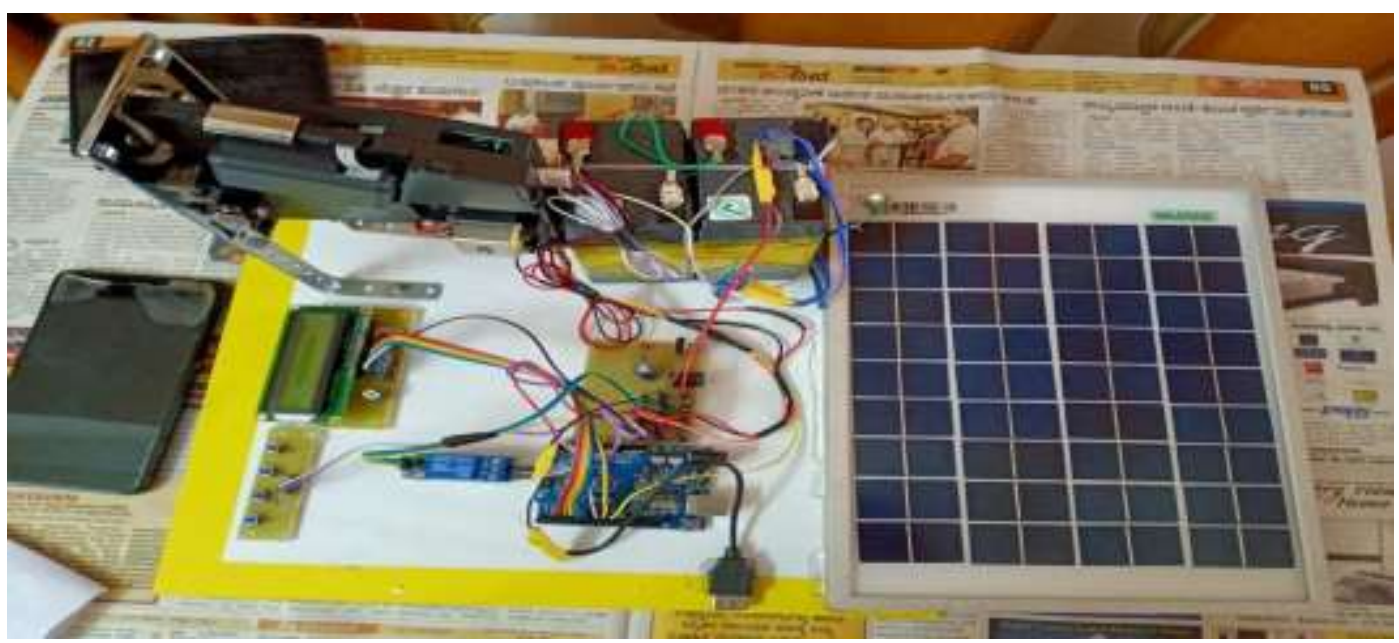

Fig. 8: Experimental Setup

\section{Working:}

At the end the working of the system can be expected as follows:

$\checkmark$ User insert coin

$\checkmark \quad$ IR sensor detects the coin

$\checkmark$ If the inserted coin is correct, then LCD display OK, otherwise returns to refund box

$\checkmark$ Display the Selection of mobile for charging

The mobiles phone can be charged in either way

1. Input power from Solar energy

2. From the regulated power supply of $230 \mathrm{~V}$ will be stepdown to $12 \mathrm{~V}$ using transformer.

In this work the microcontroller plays very important role and it works based on the instruction received by IR sensor. All the processes of the controller and relays displayed by LCD. Mobile charger pin is used to connect the mobile for charging. The amount for charging is calculated based on the number of coins inserted and mobile gets charged.

The system designed is very effective, secured and unique as it runs on solar energy. This system can be used for Televisions also with little modification. As the system uses intelligent tracking of solar energy, it utilises solar power which is essential in today's life. During summer season it can work significantly. Rural public will get benefit from this system as they won't get electricity most of the times.

$70 \%$ of the world's population uses mobile phones hence this system is useful to them since communication is becoming a vital part of human lives. Many times, it is not possible to carry mobile charger; if mobile discharges and any important work needs to be done using the mobile and charging sources are unavailable then this system is extremely useful.

This system uses solar power, which is also another major advantage because solar energy is a free source and generates more energy. This system also uses external grid power which comes into effect when solar energy is unavailable. Mostly, in rural areas this system is useful due to the problem of lack of regular electricity.

Solar energy is used in this project since it is a free source of energy that generates more energy at no expense. In the event that solar energy is absent, the system also uses external grid electricity. This will be beneficial to rural areas, as villages frequently experience power outages. 


\section{REFERENCES :}

[1] Sridevi, S. B., Suneel, A. S., \& Nalini, K. (2013). Coin based mobile charger using Solar tracking system. International Journal of Advanced Research in Electronics and Communication Engineering (IJARECE), 2(1), 741-745.

[2] Adeppa, A. (2015). Solar tracker with stepper motor control. Indian Journal of Scientific Research, 375-381.

[3] Abas, M. A., Kadir, S. A., \& Azim, A. K. (2010, December). Improved structure of solar tracker with microcontroller-based control. In 2010 Second International Conference on Advances in Computing, Control, and Telecommunication Technologies, 55-59.

[4] Nema, P., Nema, R. K., \& Rangnekar, S. (2009). A current and future state of art development of hybrid energy system using wind and PV-solar: A review. Renewable and Sustainable Energy Reviews, 13(8), 2096-2103.

[5] Ahmed, F., Naeem, M., \& Iqbal, M. (2017). ICT and renewable energy: a way forward to the next generation telecom base stations. Telecommunication Systems, 64(1), 43-56.

[6] Laura Silver et al. (2021). Use of smartphones \& social media is common across most emerging economies. Retrieved August 22, 2021, https://www.pewresearch.org/internet/2019/03/07/use-ofsmartphones-and-social-media-is-common-across-most-emerging-economies, 1-9.

[7] Gadhiya, S. A., Wandra, K. H., \& Vaghela, V. B. (2012). Role of mobile augmentation in mobile application development. IEEE International Conference on Engineering Education: Innovative Practices and Future Trends (AICERA). 1-5.

[8] Kimberly Dumke (2011). The Power of the Sun. Retrieved on August 22, 2021 from https://www.nationalgeographic.org/article/power-sun, 1-5.

[9] Eakburanawat, J., \& Boonyaroonate, I. (2006). Development of a thermoelectric battery-charger with microcontroller-based maximum power point tracking technique. Applied Energy, 83(7), 687 704.

[10] Tirmare, A. H., Khandare, V. V., \& Mali, P. S. (2015). Solar energy based mobile charger. International Journal of Research in Engineering, IT and Social Sciences, 5(6), 22-29.

[11] Varadarajan, M. S. (2012). Coin based universal mobile Battery Charger. IOSR Journal of Engineering (IOSRJEN), 2(6), 1357-1373.

[12] Yadav, Y., \& Sood, A. (2013). A Comparative Survey on Various Coin Recognition Systems Based on Image Processing. International Journal of Engineering and Computer Science, 2(11), 32723277.

[13] Chowdhury, M. E., Khandakar, A., Hossain, B., \& Abouhasera, R. (2019). A low-cost closed-loop solar tracking system based on the sun position algorithm. Journal of Sensors, 1-11. https://doi.org/10.1155/2019/3681031.

[14] Shufian, A., Rahman, M. M., Ahmed, K., Islam, R., Hasan, M., \& Islam, T. (2019). Design and implementation of solar power wireless battery charger. 1st International Conference on Advances in Science, Engineering and Robotics Technology (ICASERT), 1-5.

[15] Dai, D., \& Liu, J. (2013). Design of a practical human-powered contactless charger for cellphone. IEEE Transactions on Consumer Electronics, 59(3), 476-482. 